\title{
Survey of the use of personal protective equipment and prevalence of work related symptoms among dental staff
}

\author{
Jonathan Allsopp, Manish K Basu, Roger M Browne, P Sherwood Burge, \\ John B Matthews
}

\begin{abstract}
Objectives-Dental instruments such as the right angle or straight handpiece, air turbine, and ultrasonic scaler have the ability to produce dental aerosols containing water, saliva, microorganisms, blood, tooth particles, lubricating oil, and restorative materials. The purpose of this study was to find out whether personal protective equipment (mask, glasses) was used by dental personnel, and to investigate possible work related disease in the dental profession.

Methods-Cross sectional data were collected with a self administered questionnaire sent to 69 randomly chosen general dental practices in the West Midlands Region. All members of the dental team completed questionnaires (dentists ( $n=$ 122); nurses ( $n=115)$; hygienists ( $n=$ 86); and receptionists $(n=74)$ and answered questions on use of personal protective equipment and the prevalence of upper and lower respiratory tract, eye, and skin symptoms (reported and work related). Reception staff were included as a low exposure, control group. Also, a longitudinal study of dental hygienists was carried out on 31 people who had taken part in a similar study five years earlier.

Results-Use of a face mask and glasses differed between clinical groups with hygienists and nurses being the most and least prevalent users respectively. Although several reported symptoms were significantly more prevalent among clinical staff, only one work related symptom (skin rashes or itchy or dry skin) was reported by the clinical staff more than by the non-clinical receptionists. Among female clinical staff, age $<35$ years and atopy were the factors that predisposed to work related symptoms. Also, reported
\end{abstract}

Table 1 Questionnaire distribution and return

\begin{tabular}{|c|c|c|c|}
\hline \multirow[b]{2}{*}{ Staff } & \multicolumn{2}{|c|}{ Questionnaires } & \multirow{2}{*}{$\frac{\text { Age }(y)}{\text { Mean (range) }}$} \\
\hline & Sent $(n)$ & Returned ${ }^{*}(\%)$ & \\
\hline \multicolumn{4}{|l|}{ Women: } \\
\hline Dentists & 24 & 100 & $33.4(23.6-59 \cdot 3)$ \\
\hline Nurses & 182 & $63 \cdot 2$ & $25 \cdot 3(16 \cdot 3-61 \cdot 8)$ \\
\hline Hygienists & 124 & $69 \cdot 4$ & $34(21 \cdot 6-62 \cdot 1)$ \\
\hline Receptionists & 100 & 74 & $34 \cdot 3(17 \cdot 8-68 \cdot 3)$ \\
\hline All & 430 & $69 \cdot 5$ & $30 \cdot 8(16 \cdot 3-68 \cdot 3)$ \\
\hline \multicolumn{4}{|r|}{ 年 } \\
\hline Dentists & 141 & $69 \cdot 5$ & $40 \cdot 8(24 \cdot 2-69 \cdot 2)$ \\
\hline All & 571 & $69 \cdot 5$ & $33 \cdot 3(16 \cdot 3-69 \cdot 2)$ \\
\hline
\end{tabular}

*After two follow up requests for the return of the questionnaire. symptoms were related to duration of use of instruments that generated aerosols.

Conclusions-This study shows a low level of work related symptoms in dentistry, but highlights a group vulnerable to prolonged exposures to dental aerosols. It also supports the need for enforcement of the use of personal protective equipment among dental nurses.

(Occup Environ Med 1997;54:125-134)

Keywords: dentistry; personal protective equipment; work related symptoms

October 1989 saw the introduction of the "control of substances hazardous to health regulations" (COSHH), ${ }^{1}$ which includes microorganisms and any dust present at a substantial concentration. Inhalation is an important route by which substances may enter the body and exposure to airborne substances should be kept as low as is reasonably practicable. In dentistry, the right angle or straight handpiece (slow drill), the air turbine (high speed drill), and the ultrasonic scaler all have the ability to produce dental aerosols and up to a 30-fold increase in viable airborne bacteria may occur when such instruments are used. This increase is mainly caused by dissemination of oral organisms from the mouth rather than water or soil saprophites from the dental unit water supply. ${ }^{2-5}$ The whole dental surgery may be contaminated ${ }^{6} 7$ with up to $4.9 \times 10^{6}$ viable organisms $/ \mathrm{m}^{3}$ air being detected during the polishing of restorations. ${ }^{78}$

As well as viable organisms other less easily studied airborne contaminants are known to be present in dental surgeries which could also pose a risk to both dental staff and patients. These include blood, ${ }^{910}$ droplets of dental instrument lubricating oil, and enamel and dentine particles of respirable size. ${ }^{11-13}$ These will contain both inorganic calcium salts (mainly hydroxyapatite) and an antigenic protein matrix which could provoke an immune response.

Although the dental aerosol is a mixture of antigenic and possibly infective material, there are few published investigations of the potential occupational health risk to, or effect upon, dental staff. After the introduction of the air rotor in 1959, Grundy found that $13.5 \%$ of male dentists attributed eye and upper respiratory symptoms to its use. ${ }^{14}$ More recent epidemiological studies have indicated that contamination of dental surgeries with aerosol 
Table 2 Time present in clinical areas where instruments that generate aerosols are in use

\begin{tabular}{|c|c|c|c|c|c|c|c|c|c|}
\hline \multirow[b]{3}{*}{ Clinical staff } & \multirow[b]{3}{*}{$n$} & \multicolumn{4}{|c|}{ Air turbine or right angle or straight handpieces } & \multicolumn{4}{|c|}{ Ultra or subsonic scaler } \\
\hline & & \multicolumn{2}{|c|}{ Prevalence of use (\%) } & \multicolumn{2}{|c|}{ Duration of use } & \multirow[b]{2}{*}{$n$} & \multirow[b]{2}{*}{ Prevalence of use (\%) } & \multicolumn{2}{|c|}{ Duration of use } \\
\hline & & Air turbine & Handpiece & Mean $(y)$ & Mean (SD) (mins/day) & & & $\operatorname{Mean}(y)$ & Mean (SD) (mins/day) \\
\hline $\begin{array}{l}\text { Dentists } \\
\text { Nurses } \\
\text { Hygienists }\end{array}$ & $\begin{array}{l}112 \\
115 \\
86\end{array}$ & $\begin{array}{l}99 \cdot 2 \\
95 \cdot 7 \\
16 \cdot 3\end{array}$ & $\begin{array}{l}100 \\
95 \cdot 7 \\
83 \cdot 7\end{array}$ & $\begin{array}{r}14 \cdot 9 \\
5 \cdot 4 \\
11 \cdot 7\end{array}$ & $\begin{array}{l}280 \cdot 5(151 \cdot 0) \\
372 \cdot 4(122 \cdot 8) \\
282 \cdot 2(154.9)\end{array}$ & $\begin{array}{r}122 \\
115 \\
86\end{array}$ & $\begin{array}{l}75 \cdot 4 \\
73 \\
90 \cdot 7\end{array}$ & $\begin{array}{c}8 \cdot 5 \\
5 \\
9 \cdot 4\end{array}$ & $\begin{array}{l}134.5(142 \cdot 6) \\
190 \cdot 2(160 \cdot 2) \\
215.0(153 \cdot 2)\end{array}$ \\
\hline
\end{tabular}

is the cause of the increased prevalence of respiratory infection and serum antibodies to Legionella pneumophilia among dental staff. ${ }^{15-19}$ In a study of dental hygienists who used the ultrasonic scaler, persistent cough, nasal irritation, itchy skin, and headaches were reported at a significantly higher rate than in control groups. ${ }^{20}$ However, the most direct evidence that airborne material within the dental surgery can be a risk to health is shown by reports of a case of occupational asthma due to ivory dust, ${ }^{21}$ which is similar to human dentine, and a case of a dental student who showed exacerbation of asthmatic symptoms and ultimately an asthmatic crisis due to human enamel. ${ }^{22}$

The lack of information about work related respiratory symptoms in the dental profession prompted the present cross sectional investigation, the aim of which was to determine the use of personal protective equipment and the prevalence of upper and lower respiratory tract, eye, and skin symptoms among members of the dental team in general dental practice.

\section{Materials and methods \\ THE QUESTIONNAIRE}

The self administered questionnaire, containing 114 questions (appendix), was designed and based on that of the Medical Research Council $^{23}$ and incorporated questions from both sick building syndrome studies ${ }^{24}$ and a previous study of dental hygienists. ${ }^{20}$ Also, questions on duration of use of equipment that generates aerosols (right angle or straight handpiece, air turbine, and ultrasonic or subsonic scaler), use of personal protective equipment, surgery size, and method of ventilation were included.

Sixty nine general dental practices were chosen at random from the Family Practitioner Committee lists of Birmingham and Solihull. The questionnaire was targeted at all staff from each general dental practice, both clinical and clerical, to include groups suspected of having high (dentist, dental nurse, and dental hygienist) and low (receptionist) exposure to dental aerosols. The ques-

Table 3 Use of personal protective equipment

\begin{tabular}{lllll}
\hline & \multicolumn{5}{l}{ Prevalence of use (\%) } \\
\cline { 3 - 5 } Clinical staff & $n$ & Mask & Glasses & Both \\
\hline Dentists & 122 & $37 \cdot 7$ & $75 \cdot 4$ & $14 \cdot 7$ \\
Nurses & 115 & $10 \cdot 8$ & $23 \cdot 6$ & 0 \\
Hygienists & 86 & 79 & $64 \cdot 1$ & $43 \cdot 6$ \\
\hline
\end{tabular}

*Percentage of respondents who use PPE for more than $50 \%$ of their working time. tionnaire data, gathered between August and December, was entered into the statistical package for social sciences (SPSS PC+V3.0; SPSS, Chicago, USA). The accuracy of the input data was verified by entering it twice with subsequent comparison of the two data sets; no discrepancies were found in the data.

The design of the study, investigating all staff in randomly chosen general dental practices, inevitably resulted in unequal group sizes (table 1). In particular, the relative shortage of receptionists (low exposure, control group) is inherent in the study because each will service several clinical staff (dentists, nurses, hygienists). For comparisons between female clinical staff $(n=217)$ and receptionists $(n=71)$, the power of the study is $60 \%$ at a significance level of $5 \%$.

\section{SYMPTOMS}

Symptoms were scored in two ways. Firstly, simply with the presence or absence of a reported symptom (as in a previous study), ${ }^{20}$ and secondly, with only those symptoms which improved on days away from work (work related symptoms). ${ }^{25} 26$ As well as the use of individual symptoms or a cumulative score (person symptom index) in analyses, certain symptoms were combined as suggested by standard practice and sick building studies. $^{24-26}$ These combinations included allergic symptoms, symptoms suggestive of occupational asthma, symptoms possibly related to aerosols, and other symptoms. Allergic symptoms comprised runny nose or sneezing and eye irritation or watering: rhinitis (runny nose) is recognised relatively commonly in workers with occupational asthma. Symptoms suggestive of occupational asthma were shortness of breath, chest tightness, and wheeze (with improvement on rest days), and symptoms possibly related to aerosols included blocked or stuffy nose, dry throat, sore throat, and hoarse voice. These were originally thought to be dry symptoms due to low humidity, but it is now considered that they are related to air contamination from humidifiers; such contamination being similar to that in the dental surgery. Other symptoms included skin rashes or itchy or dry skin, and headache.

ANALYSIS OF QUESTIONNAIRE DATA

Information on sex, age, tobacco use, and atopy (defined in this study as a personal history of asthma, eczema, or hay fever) were investigated as possible predisposing factors in the prevalence of both reported and work related symptoms. Statistical investigations were performed with $\chi^{2}$ analysis including 
Table 4 Prevalence (\%) of reported symptoms

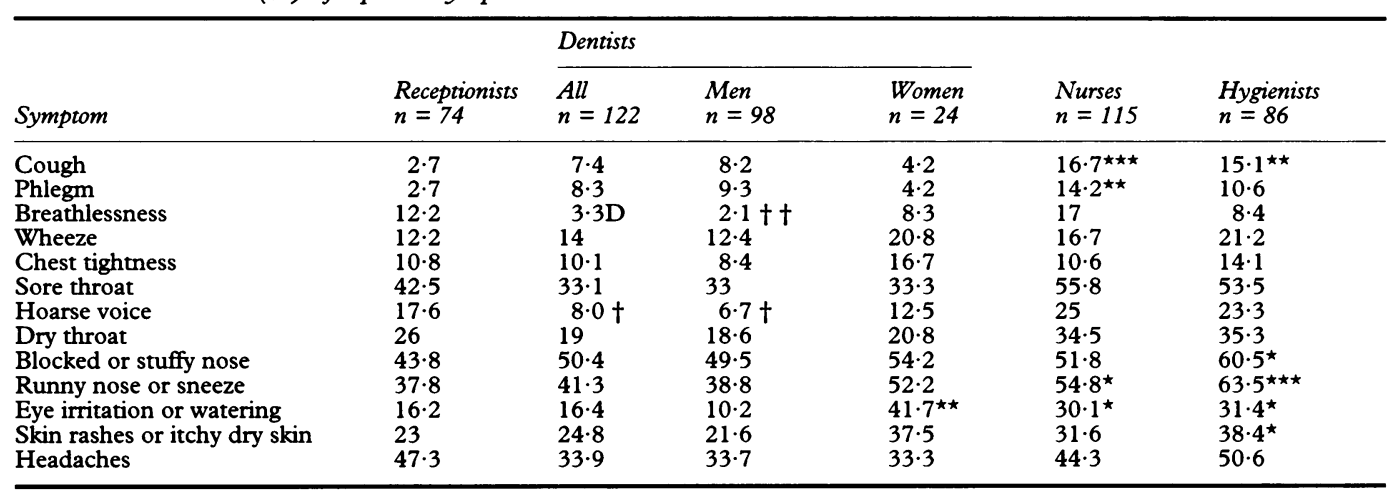

${ }^{\star} \mathrm{P}<0.05 ;{ }^{\star \star} \mathrm{P}<0.01,{ }^{\star \star \star} \mathrm{P}<0.005$; groups $>$ the receptionists by $\chi^{2}$ test.

$\dagger \mathrm{P}<0.05 ;+\mathrm{P}<0.01$; groups $<$ the receptionists by $\chi^{2}$ tests.

Table 5 Prevalence (\%) of work related symptoms

\begin{tabular}{|c|c|c|c|c|c|c|}
\hline \multirow[b]{2}{*}{ Symptom } & \multirow[b]{2}{*}{$\begin{array}{l}\text { Receptionists } \\
n=74\end{array}$} & \multicolumn{3}{|l|}{ Dentists } & \multirow[b]{2}{*}{$\begin{array}{l}\text { Nurses } \\
n=115\end{array}$} & \multirow[b]{2}{*}{$\begin{array}{l}\text { Hygienists } \\
n=86\end{array}$} \\
\hline & & $\begin{array}{l}A l l \\
n=122\end{array}$ & $\begin{array}{l}M e n \\
n=98\end{array}$ & $\begin{array}{l}\text { Women } \\
n=24\end{array}$ & & \\
\hline Cough & 0 & $3 \cdot 3$ & $4 \cdot 1$ & 0 & $6 \cdot 1$ & $1 \cdot 2$ \\
\hline Phlegm & $1 \cdot 4$ & $3 \cdot 3$ & $4 \cdot 1$ & 0 & $2 \cdot 7$ & $2 \cdot 4$ \\
\hline Breathlessness & $4 \cdot 1$ & 0 & 0 & 0 & $6 \cdot 3$ & $3 \cdot 6$ \\
\hline Wheeze & 0 & $0 \cdot 8$ & 1 & 0 & $2 \cdot 6$ & $4 \cdot 7$ \\
\hline Chest tightness & 1.4 & 2.5 & $2 \cdot 1$ & $4 \cdot 2$ & $4 \cdot 4$ & 3.5 \\
\hline Sore throat & 11 & $8 \cdot 3$ & $8 \cdot 2$ & $8 \cdot 3$ & 15 & 14 \\
\hline Hoarse voice & $8 \cdot 1$ & $2 \cdot 7$ & $2 \cdot \overline{2}$ & $4 \cdot 2$ & $8 \cdot 9$ & $9 \cdot 3$ \\
\hline Dry throat & $9 \cdot 6$ & $4 \cdot 1$ & $4 \cdot 1$ & $4 \cdot 2$ & $13 \cdot 3$ & $18 \cdot 8$ \\
\hline Blocked or stuffy nose & $15 \cdot 1$ & $7 \cdot 4$ & $8 \cdot 2$ & $4 \cdot 2$ & $9 \cdot 6$ & $8 \cdot 1$ \\
\hline Runny nose or sneeze & $12 \cdot 2$ & $9 \cdot 1$ & $9 \cdot 2$ & $8 \cdot \overline{7}$ & $18 \cdot 3$ & 12.9 \\
\hline Eye irritation or watering & $5 \cdot 4$ & $9 \cdot 8$ & $9 \cdot 2$ & $12 \cdot 5$ & $13 \cdot 3$ & $11 \cdot 6$ \\
\hline Skin rashes or itchy dry skin & $8 \cdot 1$ & 14 & $14 \cdot 4$ & $12 \cdot 5$ & $21 \cdot 9^{\star}$ & $22 \cdot 1^{\star}$ \\
\hline Headaches & $24 \cdot 3$ & $15 \cdot 7$ & $17 \cdot 3$ & $8 \cdot 3$ & 20 & $21 \cdot 2$ \\
\hline
\end{tabular}

$\star \mathrm{P}<0.05$; groups $>$ the receptionists by $\chi^{2}$ test.

Yates' correction, Fisher's exact test, and Mantel-Haenszel test as required. Also, any possible correlations between the current and cumulative generation of dental aerosols, the concomitant use of personal protective equipment, and the symptoms recorded were similarly investigated.

\section{LONGITUDINAL STUDY}

A cohort of 31 hygienists from this study had also participated in a pilot study five years earlier. ${ }^{20}$ Paired analysis (Wilcoxon) of the data from the two studies was carried out to investigate any changes in reported respiratory symptoms, use of personal protective equipment, and use of instruments that generate aerosols. Comparison of reported symptoms but not symptoms related to work was carried out as the previous questionnaire did not include information on the second.

\section{Results}

Of the questionnaires $69 \cdot 5 \%$ were returned.

Table 6 Effect of age on work related symptoms allowing for smoking habits

\begin{tabular}{|c|c|c|c|c|c|}
\hline & \multirow{2}{*}{$\begin{array}{l}\text { Work } \\
\text { related symptoms } \\
n\end{array}$} & \multicolumn{2}{|c|}{$\begin{array}{l}\text { Clinical staff } \\
n\end{array}$} & \multicolumn{2}{|c|}{$\begin{array}{l}\text { Women clinical staff } \\
n\end{array}$} \\
\hline & & $<35 y$ & $\geqslant 35 y$ & $<35 y$ & $\geqslant 35 y$ \\
\hline Non-smokers & $\begin{array}{l}0 \\
\geqslant 1\end{array}$ & $\begin{array}{l}66 \\
98 \\
\end{array}$ & $\begin{array}{r}60 \\
36 \\
1^{\star}\end{array}$ & $\begin{array}{l}52 \\
81\end{array}$ & $\begin{array}{l}28 \\
20\end{array}$ \\
\hline Smokers & $\begin{array}{l}0 \\
\geqslant 1\end{array}$ & ${ }^{13} P=$ & $\begin{array}{r}13 \\
2^{8}\end{array}$ & ${ }^{12} \mathrm{P}=$ & $\begin{array}{l}7 \\
2\end{array}$ \\
\hline
\end{tabular}

$\star$ Mantel-Haenszel $\chi^{2}$ test.
Table 1 shows the details of the respondent groups. Among all respondents the dentists were the eldest group, but the mean ages for dentists, hygienists, and receptionists were all greater than the mean age for dental nurses (one way analysis of variance (ANOVA), $P<0.05)$. Female dental staff were all of similar age except for the dental nurses, who were significantly younger (ANOVA, $\mathrm{P}<0.05$ ). Important factors in dispersal of the dental aerosol produced would be surgery volume and the method of ventilation. The mean (SD) surgery size was $61.8(66.9) \mathrm{m}^{3}(\mathrm{n}=262)$. Ventilation for $86.3 \%$ of surgeries was by simple door or window opening, $9 \cdot 7 \%$ by the use of extractor fans, and $4 \%$ by air conditioning.

WORKING PRACTICES

Table 2 shows the time present within clinical areas when instruments that produced aerosols were being used. Dental hygienists used ultrasonic or subsonic scalers most often $(P<0.05)$, for the longest time (NS), and they had the highest cumulative use (hours $x$ years; $P<0.05$ ).

There were obvious disparities between the clinical groups in their current use of personal protective equipment (table 3 ). Use of a mask was significantly different among all groups ( $P<0.0001$ ) with nurses reporting the lowest use of both face mask and protective glasses $(\mathbf{P}<0.0001)$. Simultaneous use of mask and glasses was reported by $43.6 \%$ of hygienists, which was significantly higher $(P<0.0005)$ than dentists $(14 \cdot 7 \%)$ and nurses $(0 \%)$. Among those who reported a change in use of a 
Figure 1 Person symptom index (PSI) for reported symptoms against the duration of use of the air turbine and the right angle or straight handpieces.

Figure 2 Person symptom index (PSI) for reported symptoms against the duration of use of the ultra or subsonic scaler.
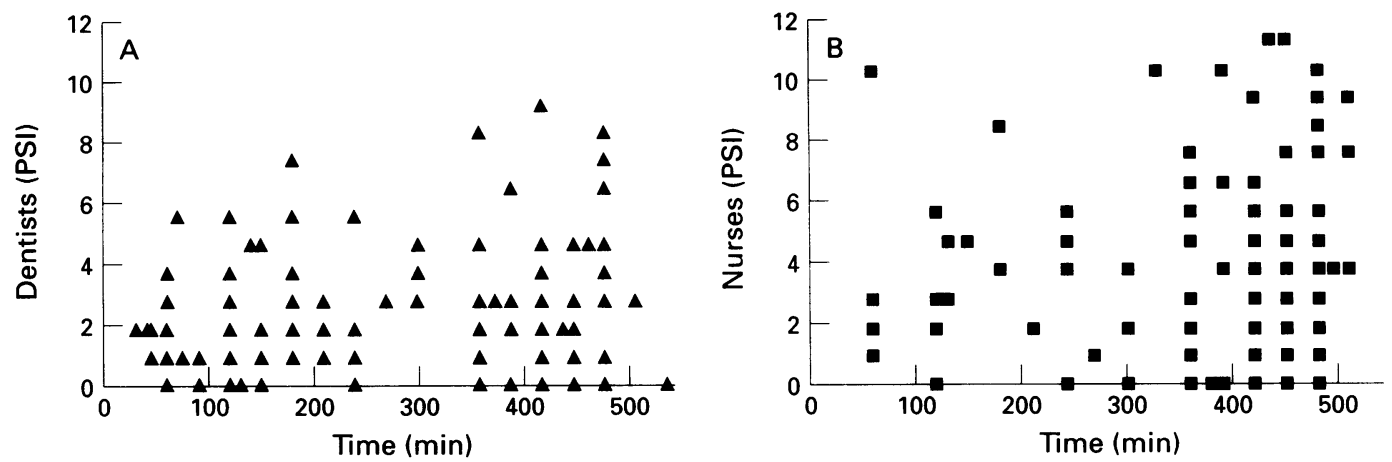

mask since qualifying the trend, in all groups, was towards increased use; however, the proportion of nurses who reported increased use was lower $(P<0.0005)$ than that of dentists or hygienists. Dentists and nurses reported increased use of glasses, but no overall increase had occurred among hygienists. Once again the actual proportion of nurses with increased use of glasses was lowest $(P<0.05)$.

\section{SYMPTOMS}

Comparison of the prevalence of reported or work related symptoms was performed
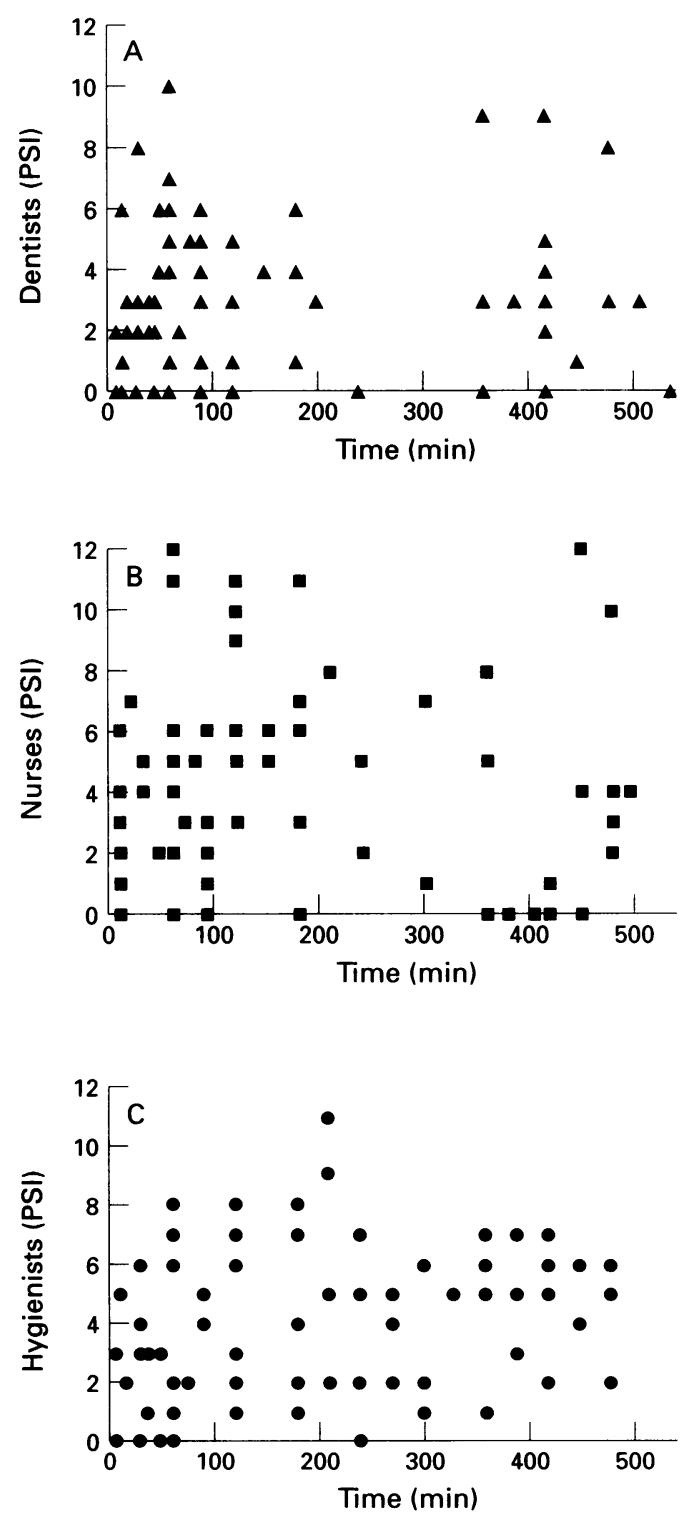

between the groups with suspected high (dentists, hygienists, and nurses) and low (receptionists) exposure to dental aerosols (tables 4 and 5). The responses indicated that reported symptoms such as persistent cough, productive cough, blocked or stuffy nose (possibly related to aerosols), runny nose or sneezing, eye irritation or watering (allergic symptoms), and skin rashes or itchy or dry skin were significantly more prevalent among female dentists, nurses, and hygienists than among the receptionists.

In nurses and hygienists, rather than in the receptionists, only skin rashes or itchy or dry skin from the work related symptoms was significantly more prevalent (table 5). Among the clinical staff, the mean (SD) work related person symptom index for all women $(1 \cdot 3$ (1.95)) was significantly higher $(P<0.05$; Mann-Whitney, two tailed) than that for the men, all of whom were dentists $(0.84(1.48))$. The person symptom index for the female clinical staff was also higher than that for the non-clinical receptionists (all women; 1.0 $(1 \cdot 76), P=0.05)$, although the receptionists and the male dentists were similar $(P=0.91$; Mann-Whitney, two tailed). Analysis of the data grouped by age ( $<35$ and $>35$ years; Mantel-Haenszel test) showed no age dependent effects on the difference in work related symptoms for the female clinical staff compared with non-clinical receptionists.

Investigation of age, atopy, and smoking habits was performed among the female staff. Young clinical staff (< 35 years) were more likely to have work related symptoms ( $\mathrm{P}<$ 0.01 ), although this was not the case among receptionists. Atopic clinical staff were likely to have two or more work related symptoms ( $P<0.0001)$, but among receptionists those with atopy were no more likely than those without to have this number of symptoms. Table 6 shows the data on smoking habits, age, and presence of work related symptoms among clinical staff. Analysis of the data indicated that smoking masked the age effect on work related symptoms. Thus, although young, female, clinical staff $(<35$ years) who did not smoke were more likely to have work related symptoms $(P<0.05)$ this did not apply to those who smoked $(P=0.09)$.

\section{WORKING PRACTICES AND SYMPTOMS}

There was no apparent correlation between daily use of instruments that produce aerosols 
Figure 3 Person symptom index (PSI) for work. related symptoms against the duration of use of the air turbine and the right angle or straight

handpieces.

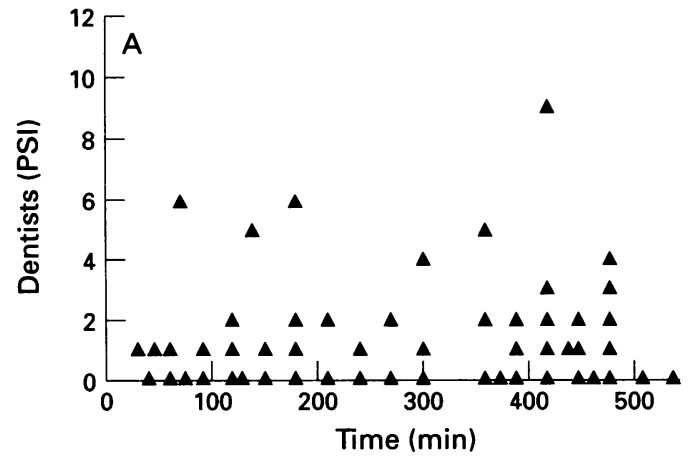

and the number of symptoms reported. However, compared with people with few symptoms $(<7)$, a significantly increased proportion of people with many symptoms $(>7)$ were found to use the air turbine (and right angle or straight handpiece) for $>360$ minutes a day ( $P<0.01$ for dentists and nurses, fig 1$)$, or the ultrasonic scaler for $>60$ minutes a day, or both $(P<0.05$ for all clinical groups, fig 2$)$. Investigation of those people with high estimated durations of exposure to the dental aerosol $(<360$ minutes for air turbine or right angle or straight handpiece and $>60$ minutes for the ultrasonic scaler) showed that more symptoms $(>7)$ were prevalent among those who were young $(<35$ years of age, $P<0.05)$, atopic $(P<0.0005)$, and female $(P<0.05)$. Smoking habits had no apparent effect. There seemed to be no relation between duration of use of instruments that produced aerosols, use of personal protective equipment, and work related symptoms, although a small group remained with high durations and many symptoms (fig 3).

\section{LONGITUDINAL STUDY}

Among the cohort of 31 hygienists, paired analysis showed an increased mean (SD) duration of use of ultrasonic or subsonic scalers from 129 (116) to 222 (165) minutes a day (Wilcoxon, $\mathrm{P}<0.01$ ) over the five year period. There was a concomitant, although not significant, increased use of personal protective equipment from $54 \%$ to $71 \%$ (average for mask and glasses). Use of personal protective equipment by this cohort of hygienists did not differ from the 55 hygienists who had not participated in the previous study $(P<0.825$ for mask and glasses). This finding suggests that the previous study had not influenced behaviour and that there had probably been a general increase in use of personal protective equipment by hygienists over the past five years. Nasal irritation was the only reported symptom that had increased in prevalence, from $43 \%$ to $70 \%(P<0 \cdot 05)$. However, this increase was not related to increased use of a scaler by individual people.

\section{Discussion}

This is the first study to investigate the prevalence of both reported and work related symptoms within the dental profession. Interestingly, none of the symptoms investigated in the questionnaire, including eye irrita-

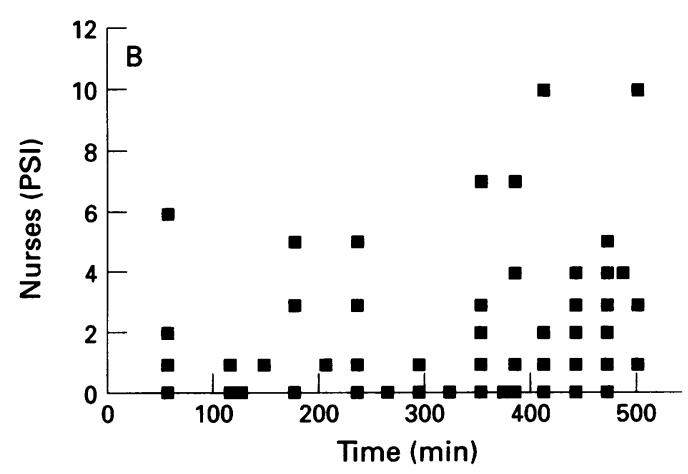

tion, were affected by the use of a mask or glasses. This result may have been expected as it is difficult to elucidate small work related effects in cross sectional surveys. ${ }^{27}$ Although the use of protective glasses and a mask at all times when operative dentistry is being performed is advisable, there are large differences between the members of the dental team in their use of personal protective equipment (table 3). The pattern of use may be affected by working practices and knowledge aquired before qualification, ${ }^{162028}$ although most dental nurses and receptionists enter directly into employment at their general dental practices without previous training or employment. Dental nurses have been shown to have a significantly lower perception of clinical dental hazards than dentists and hygienists in both this study $(P<0.05)$ and others. ${ }^{16}{ }^{20}$ However, the COSHH regulations place a duty on employers to provide information, instruction, and training to employees on the hazards of their working environment. ${ }^{1}$ The questionnaire data show dental nurses to be ill informed and taking few steps to protect themselves.

A potentially important aspect of the use of personal protective equipment in dental practice, not studied here, is the availability and suitability of different types of face masks and glasses that offer different levels of protection. Although all masks will act as a physical barrier to larger particles or droplets only some seem to be effective filters. ${ }^{29}{ }^{30}$ However, even these may not necessarily prevent inhalation of particles of respirable size which could pass around the edge where the glasses fit poorly. Similarly, various forms of eye shield have been advocated over the years, all of which reduce the hazard from large particles (ballistic splatter) but have variable effectiveness against an aerosol, depending on their closeness of fit. High specification masks and glasses can be costly, alarming to patients, and uncomfortable to wear. More data on the nature and effect of airborne contamination in the dental surgery are required before specific guidelines can be produced for the use and level of protection required.

The reported symptoms found to be significantly more prevalent among the dental team than the controls (receptionists) are similar to those found by Basu et al and include allergic symptoms and symptoms possibly related to aerosols. ${ }^{20}$ The chest symptoms of cough and phlegm (productive cough), which may be 
associated with occupational asthma, ${ }^{26}{ }^{31}$ were significantly increased in this study as in that of Basu et $a l,{ }^{20}$ although there were no significant increases in the symptoms classically associated with occupational asthma-namely, breathlessness, wheeze, and chest tightness. More importantly, however, when work related symptoms were assessed, only skin rashes or itchy or dry skin were significantly increased in nurses and hygienists. This result is similar to that of Murtomaa, who reported that dental nurses had a significantly increased prevalence of work related rash or allergic reactions. ${ }^{16}$ Guidelines on cross infection require dental practitioners to wear rubber gloves, usually latex, for long periods each day. Increasing numbers of dermatological problems are being reported, ${ }^{32}$ which may have an immunological aetiology but are more commonly due to irritation. The generally higher prevalence of work related skin problems in clinical staff in this study may be due to irritation. That this increase was only significant for dental nurses and hygienists may indicate different patterns of use of gloves between clinical groups. Unfortunately, no questions on use of gloves were incorporated in the questionnaire. However, the dental nurses in the study of Murtomaa considered frequent contact with dental materials a major health hazard. ${ }^{16}$

Although not specifically questioned on the topic, 14 of 201 (7\%) nurses and hygienists in this study, reported respiratory, eye, or skin problems associated with glutaraldehyde or other sterilising solutions or sprays. As problems associated with glutaraldehyde have been recorded, ${ }^{33}$ the data suggest that the use of such materials should be monitored and only used under controlled situations.

A dose related response for reported symptoms was suggested as a high duration of use of the air turbine and right angle or straight handpiece or ultrasonic scaler was associated with many reported symptoms among a distinct subset of the respondents. On the other hand, few reported many symptoms with low use of the instruments. Analysis of the questionnaire data suggests that those predisposed to both reported and work related symptoms are young women ( $<35$ years) who are often atopic. Studies of workers in other environments which could be described as having similarities to the dental surgery have also reported a similar group. Thus, women show a significantly higher number of work related symptoms in sick building syndrome, which affects a considerable proportion of people working in air conditioned buildings with airborne particles and bacteria (from humidifiers) being possible causes. ${ }^{34} 35$ Furthermore, as in this study, younger staff with shorter service were found to have increased respiratory illness in the postmortem room, ${ }^{35}$ another site of generation of organic aerosols. Atopy was suggested by Basu et al as a factor in the predisposition of dental hygienists (women) to certain symptoms. ${ }^{20}$ Interestingly, atopy is also a risk factor in exposure to organic material in novice seasonal farm workers, laboratory animal technicians, and those in several other environments. ${ }^{26}{ }^{36}$ Atopy is also a predisposing factor to allergic bronchoconstriction due, in particular, to high molecular weight organic compounds. ${ }^{2631}$

From this study it seems that the level of work related symptoms experienced in dentistry is lower than that in the benign sick building syndrome (except for skin symptoms), and is substantially lower than that experienced in agriculture where persistent and productive cough (phlegm) are found in $12 \%-55 \%$ of workers and chest tightness and wheezing in $12 \%-33 \% .{ }^{37} 38$ Interestingly, the prevalence of the work related symptoms among receptionists in the present study closely matched those of healthy workers in naturally ventilated buildings, ${ }^{24} 25$ and tends to support the validity of the self administered questionnaire used here.

Although this study has shown that the dental team are subject to a low level of work related symptoms, there does seem to be a small, but significant group of subjects at risk. Young female clinical staff who are usually atopic are the most susceptible and their symptoms seem related to use of instruments that generate aerosols. In terms of work practice, we conclude that the provision of appropriate personal protective equipment for all clinical staff by their employers should be a high priority, as this is both reasonably practical and legally required. This study shows that such provision is particularly lacking among dental nurses.

This research was funded by a grant from the Health and Safety Executive.

Appendix: Questionnaire, health effects of dental aerosols

This questionnaire is about contaminated air in the dental surgery. As a dentist or a member of the dental team you work in/or near to this environment. The purpose of this study is to assess any health implications associated with working in this environment.

This questionnaire appears vast but don't be put off as it will only take minutes to answer.

This sheet will be detached and kept separate from the questionnaire and in this way all of your answers will be kept totally confidential.

\section{NAME:-}

When you have completed the questionnaire by ticking the appropriate boxes place it in the stamped, addressed envelope provided. There is one envelope per person. This will ensure that confidentiality is maintained.

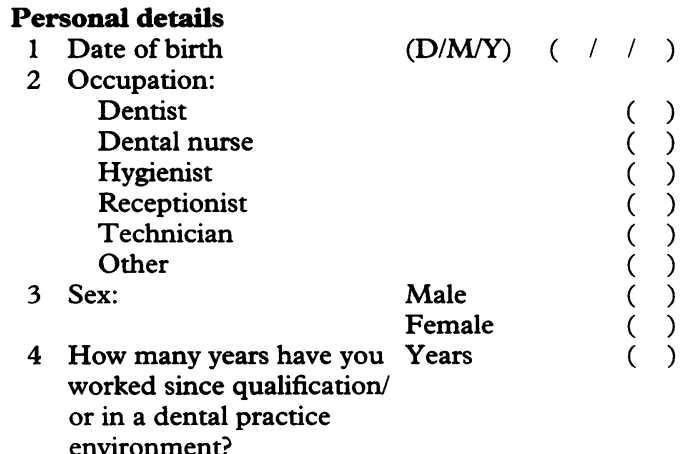


Working conditions

5 What is the approximate size of the room in which you work for the majority of your time?

Length (metres) ( ) Breadth (metres) ( )

6 What is the main form of ventilation for this room?

a) Air conditioning

b) Extractor fan

c) Door/window open

7 Do you have a ducted air heating system?

8 Do you use an air turbine, or is one used in

the room in which you spend the majority

of your time?

Do you use a right angle

/straight handpiece

or is one used in the room

in which you spend

the majority of your time?

If "No" to both, go to

Question 17.

9 How long have you worked with a water cooled

right angle/straight handpiece and/or air turbine, or in an environment where they have been used?

10 Estimate the average amount of time each day you are working with these instruments or in an environment where they are being used

11 Indicate which of the following statements most closely describes your present use of a face mask while these instruments are being used.
a) always
b) $75-99 \%$ of the time
c) $50-74 \%$ of the time
d) $25-49 \%$ of the time
e) $1-24 \%$ of the time
f) never

12 Has your use of the face mask changed since qualification?

13 If "yes", has it:
a) just started
b) increased a lot
c) increased a bit
d) remained the same
e) decreased a bit
f) decreased a lot
g) stopped completely

14 Indicate which of the following statements most closely resembles your present use of glasses or visor while these instruments are being used.

a) always

b) $75-99 \%$ of the time

c) $50-74 \%$ of the time

d) $25-49 \%$ of the time

e) $1-24 \%$ of the time

f) never

15 Has your use of glasses or visor changed since qualification?

16 If "Yes", has it:
a) just started
b) increased a lot
c) increased a bit
d) remained the same
e) decreased a bit
f) decreased a lot
g) stopped completely

Yes
No
17 In your present job is an ultrasonic or
subsonic water-cooled scaler used in the

$\begin{array}{ll}\text { Yes } & (\text { ) } \\ \text { No } & (\text { ) } \\ \text { Yr/Mth }(1)\end{array}$

room in which you spend the majority of your time?

If "No", go to Question 26.

18 How long have you worked with a water cooled

ultrasonic or subsonic scaler, or in an environment where one has been used?

19 Estimate the average amount of time each day you are working with an ultrasonic or subsonic scaler, or in an environment where one is being used.

$\operatorname{Hr} / \operatorname{Min}($ / )

20 Indicate which of the following statements most closely describes your current use of a face mask while this instrument is being used.
a) always
b) $75-99 \%$ of the time
c) $50-74 \%$ of the time
d) $25-49 \%$ of the time
e) $1-24 \%$ of the time
f) never

21 Has your use of the face mask changed since qualification?

22 If "Yes", has it:
a) just started
b) increased a lot
c) increased a bit
d) remained the same
e) decreased a bit
f) decreased a lot
g) stopped completely

23 Indicate which of the following most closely describes your use of glasses or visor while this instrument is being used.
a) always
b) $75-99 \%$ of the time
c) $50-74 \%$ of the time
d) $25-49 \%$ of the time
e) $1-24 \%$ of the time
f) never

24 Has your use of glasses or visor changed since qualification?

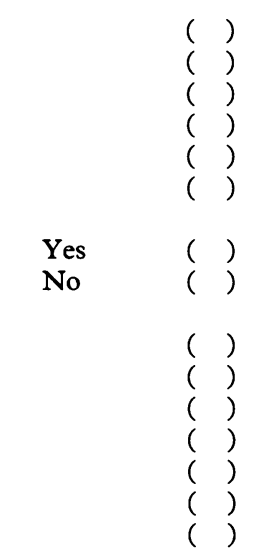

25 If "Yes", has it:
a) just started
b) increased a lot
c) increased a bit
d) remained the same
e) decreased a bit
f) decreased a lot
g) stopped completely

$\begin{array}{ll} & (\text { ) } \\ & (\text { ) } \\ & (\text { ) } \\ & (\text { ) } \\ & (\text { ) } \\ & \\ \text { Yes } & (\text { ) } \\ \text { No } & (\text { ) }\end{array}$

Health

The following are some questions about your health. ( ) Please answer "Yes" or "No" if possible. If in doubt, ( ) answer "No".

( ) 26 Do you usually cough first thing

( )

()

( )

$$
\begin{array}{lll}
27 & \begin{array}{l}
\text { Do you usually cough during the } \\
\text { day or at night in the winter? }
\end{array} & \text { Yes } \\
& \text { No } & \text { ( ) } \\
\text { If "Yes" to } 26 \text { or } 27 \text { answer } & &
\end{array}
$$

( ) questions 28-31.

If "No", go to Question 32 .

( )

( )

28 Do you cough like this on most days for as much as 3 months each year?

29 Is your cough better on days away from work?

$\begin{array}{ll}\text { Yes } & (\text { ) } \\ \text { No } & (\text { ) } \\ \text { Yes } & (\text { ) } \\ \text { No } & (\text { ) }\end{array}$


30 Is your cough better on holidays? Yes

31 When did your cough first start? No

Phlegm

32 Do you usually bring up any phlegm from

your chest first thing in the morning in the winter?

If "No", go to question 38 .

33 Do you usually bring up any phlegm from your chest during the day or night in the winter? If "Yes" to Question 32 or 33, please answer Questions 34 to 37. If "No" go to Question 38.

34 Do you bring up phlegm from your chest on most days for as much as 3 months each year?

35 Do you bring up less phlegm from your chest on days away from work

36 Do you bring up less phlegm from your chest on holiday?

37 When did you first start bringing up phlegm?

On your worst day in the last 6 months:

38 Were you troubled by shortness of breath when hurrying on level Yes ground or walking up a slight hill No If "Yes", answer questions 39-44. If "No", go to Question 45.

39 Did you get short of breath walking with other people of your own age on level ground? If "Yes", answer Questions 40 and 41, if "No", go to Question 42:

40 Do you have to stop for breath when walking at your own pace on level ground?

If "Yes", answer Question 41. If "No", go to Question 42:

41 Were you short of breath

\section{Yes}

No

Yes
No

Yes

No

Yes

No

Yes

No

Yes

No

Yes

No

$\operatorname{Mth} / \mathrm{Yr}(1)$

Breathlessness

57 When

99 Is your breathing absolutely normal between attacks?

50 Is your wheezing better on days away from work?

51 Is your wheezing better on Is your whe
holiday?

When

( )

\section{) Chest tightness}

53 Does your chest ever become tight or your breathing become difficult? If "No", go to Question 58.

54 If "Yes", how often is this?
a) most days
b) most weeks
c) most months
d) less often

55 Is your chest tightness better on days away from work?

56 Is your chest tightness better on holidays?

Yes No

\begin{tabular}{|c|c|}
\hline \multirow{2}{*}{\multicolumn{2}{|c|}{$\begin{array}{l}\text { Yes } \\
\text { No }\end{array}$}} \\
\hline & \\
\hline Yes & ( ) \\
\hline No & ( ) \\
\hline Yes & \\
\hline No & $($ ) \\
\hline
\end{tabular}

$\mathrm{Mth} / \mathrm{Yr}$

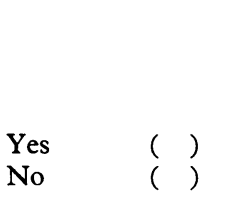

\section{Smoking}

59 Have you ever smoked as much as 1 cigarette a day (or 1 cigar a Yes week or an ounce of tobacco No a month)? If "No" to both Questions 58 and 59, please go to question 69 . If "Yes", please answer questions 60-68.

60 How old were you when you started to smoke regularly?

$\begin{array}{ll}\text { Yes } & (\text { ) } \\ \text { No } & (\text { ) }\end{array}$

No

61 ow many cigarettes do (did) you usually smoke per day?

62 Do you smoke hand-rolled cigarettes?

Mth/Yr washing or dressing?

42 Is your breathlessness better on days away from work?

Yes

No

Yes

No

43 Is your breathlessness better on holidays?

44 When did your breathlessness first start?

\section{Wheezing}

45 Does your chest ever sound wheezy or whistling?

If "No" go to Question 53

46 If "Yes", how often does your chest sound wheezy?
a) most days
b) most weeks
c) most months
d) less often

47 Have you had attacks of shortness of breath with wheezing?

Yes

48 If "Yes", how often do you get these attacks?
a) most days
b) most weeks
c) most months
d) less often

$\begin{array}{ll}\text { Yes } & (\text { ) } \\ \text { No } & (\text { ) }\end{array}$

Yes $\quad($ )

No ( )

$\operatorname{Mth} / \mathrm{Yr}($ / )

If "Yes" go to 63. If "No" go to 64.

63 How much tobacco do (did) you usually smoke per week in this way?

64 Do (did) you smoke a pipe?

65 How much pipe tobacco do (did) you usually smoke per week?

66 Do (did) you smoke cigars?

67 How many cigars do (did) you usually smoke per day?

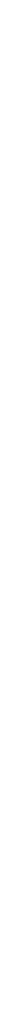


71 Is your throat better on days away from work? Yes No

72 Is your throat better on holidays? Yes No

73 When did these episodes first start? Mth/Yr

\section{Hoarse voice}

74 In the past 12 months have you had more than 2 episodes of hoarseness of the voice? Yes If "No", go to Question 79.

75 If "Yes", do you get these on:
a) most days
b) most weeks
c) most months
d) less often

76 Is your voice better on days away from work? Yes

No

77 Is your voice better on holidays? Yes No

78 When did these episodes first start?

Mth/Yr

\section{Dry throat}

79 In the past 12 months have you had more than 2 episodes of a Yes a dry throat? If "No", go to Question 84.

80 If "Yes", do you get these on
a) most day
b) most weeks
c) most months
d) less often

81 Is your throat better on days away from work?

82 Is your throat better on holidays? Yes

83 When did these episodes first start?

$\mathrm{Mth} / \mathrm{Yr}$

\section{Blocked or stuffy nose}

84 In the past 12 months have you had more than

2 episodes of blocked or stuffy nose? If "No", go to Question 89.

85 If "Yes", do you get this:
a) most days
b) most weeks
c) most months
d) less often

86 Is this better on days away from work?

Is this better on holidays?

88 When did these episodes first start?

\section{Runny nose or sneezing}

89 In the past 12 months have you had more than 2 episodes of runny nose or sneezing?

If "No", go to Question 94.

90 If "Yes", do you get this on:
a) most days
b) most weeks
c) most months
d) less often

91 Is this better on days away from work?

Yes

No

92 Is this better on holiday?

93 When did these episodes first start?

$\mathrm{Mth} / \mathrm{Yr}$

$(1)$

Eye irritation or watering

94 In the past 12 months have you had more than 2 episodes of itching, irritation or watering of the eyes? If "No", go to Question 99.

95 If "Yes", do you get this:
a) most days
b) most weeks
c) most months
d) less often

96 Is this better on days away from work?

97 Is this better on holidays?

98 When did these episodes first start?

$\mathrm{Mth} / \mathrm{Yr} \quad(1)$

\section{Rashes, itchy or dry skin}

99 Do you suffer from skin rashes, itchy or dry skin, on your hands Yes $($ ) or face? If "No", go to Question 104.

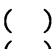

(

( )

( )

( )

( )

( )

( )

( )

( )

\section{$1)$}

eadaches

104 Do you suffer from headaches (excluding common colds)?

If "No", go to Question 109.

( ) 105 If "Yes", do you get these on:
a) most days
b) most weeks
c) most months
d) less often

106 Are these better on days away from work?

107 Are these better on holidays?

108 When did these episodes first start?

109 Do you take any treatment for your eyes, nose, throat or chest? If "Yes", please specify.

110 Do you think anything that you are exposed to at work affects your eyes, nose, throat
b) most days
c) most month
d) less often details.

112 Have you even had asthma? Yes ( )

114 Have you ever had regular winter No ( ) bronchitis?

Yes $\quad($ )


1 Her Majesty's Stationary Office. Control of substances haz ardous to health regulations. London: HMSO, 1988. (S Nol657.)

2 Belting CM, Haberfelde GC, Juhl LK. Spread of organism from dental air rotor. $\mathcal{F}$ Am Dent Assoc 1964;68:648-51.

3 Larato DC, Ruskin PF, Martin A. Effect of a dental air tur bine on the bacterial counts in air. F Prosthet Dent 1966 16:758-65.

4 Holbrook WP, Muir KF, Macphee IT, Ross PW. Bacteriological investigation of the aerosol from ultrasonic scalers. British Dental fournal 1978;144:245-7.

5 Glenwright HD, Knibbs PJ, Burdon DW. Atmospheric contamination during use of an air polisher. British Dental fournal 1985;159:294-7.

6 Burton WE, Miller RL. The role of aerobiology in dentistry. In: Dimmick RL, ed. Symposium on aerobiolog 1963. Oakland, CA: Naval Biology Laboratory, Nava Supply Center, 1965:87-94

7 Miller RL, Burton WE, Spore RW. Aerosols produced by dental instrumentation. In: Dimmick RL, ed. Symposium on aerobiology 1963. Oakland, CA: Naval Biology Laboratory, Naval Supply Center, 1965:97-120.

8 Micik RE, Miller RL, Ryge G, Mazzarella MA. Microbial aerosols discharged from the oral cavity of dental patients. F Dent Res 1967;243:97.

9 Krammer RV. The dentist's health: high-speed rotary equipment as a risk factor. Quintessence International 1985;5:367-71.

10 Checchi L, Matarasso S, Pirro P, D'Achille C. Topographical analysis of the facial areas most susceptible to infection with transmissible diseases in dentists. International fournal of Periodontics and Restorative Dentistry 1991;11:165-72.

11 Kazantzis G. Air contamination from high-speed drills. Proceedings of the Royal Society of Medicine 1961;54:242-4.

2 Nixon GS, Tilston DRG. Inhalation of oil particles from air turbine handpieces. British Dental foumal 1965;119: $114-7$

13 Grundy JR. Enamel aerosols created during use of the air turbine handpiece. 7 Dent Res 1967;46:409-16.

14 Grundy JR. Symptoms attributed to the air turbine. Dental Practitioner 1966:17:17-20.

15 Shreve WB, Tow HD. Bacteriological and serological surveillance of dentists exposed to dental aerosols. Bull Tokyo Med Dent Univ 1981;22:151-7.

16 Murtomaa $\mathrm{H}$. Work related complaints of dentists and dental assistants. Int Arch Occup Environ Health 1982;50 231-6.

17 Rosen S, Schmakel D, Schoener M. Incidence of respiraory disease in dental hygienists and dieticians. Clinical Preventive Dentistry 1985;7:24-5.

18 Davies KJ, Herbert A-M, Westmoreland D, Bagg J. Seroepidemiological study of respiratory virus infection among dental surgeons. British Dental foumal 1994;176: $262-5$.
19 Reinthaler F, Mascher F, Stunzner D. Legionella pneumophila: seroepidemiologic studies of dentists and denta personnel in Austria. Zentralblatt für Bakteriologi Mikrobiologie und Hygiene B 1987;185:164-70.

20 Basu MK, Browne RM, Potts AJC, Harrington JMA. A survey of aerosol-related symptoms in dental hygienists. $\mathscr{f}$ Soc Occup Med 1988;38:23-5.

21 Armstrong RA, Neill P, Mossop R'T. Asthma induced by vory dust: a new occupational cause. Thorax 1988;43: $737-8$.

22 Housholder GT, Chan JT. Tooth enamel dust as an asthma stimulus. Oral Surgery Oral Medicine Oral Pathology 1993;75:599-601.

23 Medical Research Council's Committee on the Aetiology of Chronic Bronchitis: standardized questionnaires on respiratory symptoms. BMF 1960;ii: 1665 .

24 Finnegan MJ, Pickering CAC, Burge PS. The sick buildin syndrome: prevalence studies. BMF 1984;289:1573 5 .

25 Robertson AS, Burge PS, Hedge A, Sims J, Gill FS, Finnegan $\mathrm{M}$, et al. Comparison of health problems related to work and environmental measurements in two office buildings with different ventilation systems. $B M \mathcal{F}$ 1985;291:373-6.

26 Burge PS. Occupational asthma. In: Brewis RAL, Gibson GJ, Geddes DM, eds. Respiratory medicine. London: Bailliere Tindall, 1990:704-21.

27 Becklake MR. Chronic airflow limitation: its relationship to work in dusty occupations. Chest 1985;88:608-17.

28 Roberts-Harry TJ, Cass AE, Jagger JD. Ocular injury and infection in dental practice. A survey and a review of the literature. British Dental fournal 1991;1 70:20-2.

29 Pippen DJ, Verderame RA, Weber KK. Efficacy of face masks in preventing inhalation of airborne contaminants. f Oral Maxillofac Surg 1987;45:319-23.

30 Hogan B, Samaranayake P. The surgical mask unmasked. review. Oral Surgery 1990;70:34-6.

31 Chan-Yeung M, Lam S. Occupational asthma. Am Rev Respir Dis 1986;133:688-703.

32 Food and Drug Administration. Allergic reactions to latexcontaining medical devices. Food and Drug Administration Medical Bulletin 1991.

33 Burge PS Occupational risks of glutaraldehyde $B M F$ 1989;299:342.

34 Pickering CAC. Building sickness syndrome. Respir Med 1989;83:91-2

35 Hall AJ, Aw TC, Harrington JM. Morbidity survey of post mortem room staff. 7 Clin Pathol 1991;44:433-5.

36 Cookson WOCM, Ryan G, MacDonald S, Musk AW. Atopy, non-allergenicbronchial reactivity, and pas history as determinants of work related symptoms in ceasonal grain handlers. Br f Ind Med 1986;43:396-400.

37 Respiratory symptoms in farmers [editorial]. Lancet 1989;i: $1054-5$

38 Donham KJ. Health effects from work in swine confinement buildings. Am ₹ Ind Med 1990;17:17-25. 